\title{
Estratégias de tratamento para lesões traumáticas de teto de vacas leiteiras
}

\author{
Strategies for the treatment of traumatic teat lesions in dairy cattle
}

Alexander Starke ${ }^{[]]}$, Dirk Ahlers ${ }^{[b]}$, Rüdiger Daniel Ollhofff[c, Ivan Roque de Barros Filho ${ }^{[d]}$, Martina Hoedemaker ${ }^{[e]}$

[a] Médico-veterinário, Dip. ECBHM, Klinik für Rinder der Stiftung Tierärztliche Hochschule Hannover, Hannover Alemanha, e-mail: alexander.starke@tiho-hannover.de

[b] Médico-veterinário, Klinik für Rinder der Stiftung Tierärztliche Hochschule Hannover, Hannover - Alemanha, e-mail: dirk. ahlers1@freenet.de

[c] Médico-veterinário, professor titular do PPG em Ciência Animal da Pontifícia Universidade Católica do Paraná (PUCPR), São José dos Pinhais, PR - Brasil, e-mail: ollhoff@gmail.com

[d] Médico-veterinário, professor adjunto da Universidade Federal do Paraná (UFPR), Curitiba, PR - Brasil, e-mail: ivanbarf@ ufpr.br

[e] Médica-veterinária, professora, Ph.D., Dip. ECAR, Dip. ECBHM, Klinik für Rinder der Stiftung Tierärztliche Hochschule Hannover, Hannover - Alemanha, e-mail: Martina.Hoedemaker@tiho-hannover.de

\section{Resumo}

As afecções do úbere de vacas leiteiras estão entre os maiores motivos de perdas e descarte das vacas. As lesões traumáticas do teto em vacas de leite foram superficialmente abordadas pela literatura médico-veterinária brasileira nos últimos anos, apesar da crescente tecnificação e especialização do rebanho leiteiro. Os médicos-veterinários que assistem vacas leiteiras não possuem literatura técnica em português à qual possam recorrer. Esta nota técnica reúne as experiências europeia e brasileira sobre $\mathrm{o}$ assunto e descreve, de maneira ilustrativa, as possíveis condutas e estratégias de tratamento diante de uma lesão traumática do teto bovino, complicada ou não por uma mastite.

Palavras-chave: Bovino. Teto. Lesões. Tratamento. Conduta.

\section{Abstract}

Udder affections of dairy cows are some of the main reasons for milk production losses and cow culling. Teat lesions in dairy cattle have been researched superficially in the Brazilian literature lately, despite the growing mechanization and specialization of the Brazilian dairy herds. Veterinarians who work with dairy cows cannot refer to technical literature in Portuguese language. This article unites the European and Brazilian experiences on this subject and describes, in an illustrative manner, strategies to treat traumatic teat lesions of dairy cows, complicated or not by mastitis.

Keywords: Bovine. Teat. Lesion. Therapy. Management. 


\section{Introdução}

0 uso de arame farpado na década de 40 do século passado foi relacionado por Götze (1942) como um dos principais fatores na incidência de graves lesões de tetos das vacas.

A seleção de vacas para maior produção láctea, com consequente aumento do tamanho e volume do úbere, estábulos inadequados, casqueamento incorreto ou inexistente, fez crescer a proporção de lesões por pisaduras (EDLER, 1993).

Para um prognóstico correto e conduta terapêutica mais adequada, é essencial caracterizar o tipo, a forma, a extensão, a localização, o tempo de lesão, bem como a presença ou não de mastite no quarto do úbere lesionado (GRUNERT; AHLERS, 1996).

Em função da insuficiência de artigos nacionais englobando os aspectos clínicos e terapêuticos das lesões de teto de forma abrangente, a presente nota técnica tem como objetivo proporcionar um material prático e esclarecedor no tocante às lesões de teto nos bovinos de leite, que são os mais acometidos pelo problema.

\section{Tipos de lesões traumáticas de teto}

De acordo com a profundidade do traumatismo causador das lesões de teto, pode-se distinguir entre as (lesões) fechadas sem solução de continuidade da pele, como as ablações de mucosa intracisternais, cicatriciais e feridas não perfurantes (Figura $1 \mathrm{a}, \mathrm{b}$ ) e perfurantes, adentrando a cisterna do teto (Figura 2, escorrimento lácteo). Nos ferimentos em que não houve prévia limpeza dos tetos, com presença de exsudatos ressecados e sujidades, a saída do leite pode passar facilmente despercebida. Pela forma, é possível diferenciar as fissuras horizontais, transversais e diagonais, assim como feridas descascadas e em flap (Figuras 1 a, b). Na avaliação da extensão da ferida, deve-se observar se a lesão atingiu o canal do teto, qual o comprometimento deste, considerando-se o grau de alteração de sua função e fechamento (Figura $1 \mathrm{~b}$ ).

Em casos extremos, o teto todo poderá ter sido arrancado. Basicamente pode-se encontrar combinação de diferentes tipos de lesão de tetos. Tanto uma lesão recente como uma mais antiga podem sofrer complicação por mastite; portanto, é fundamental que seja realizado exame da secreção láctea rotineiramente (EDLER, 1993, GRUNERT; AHLERS, 1996).

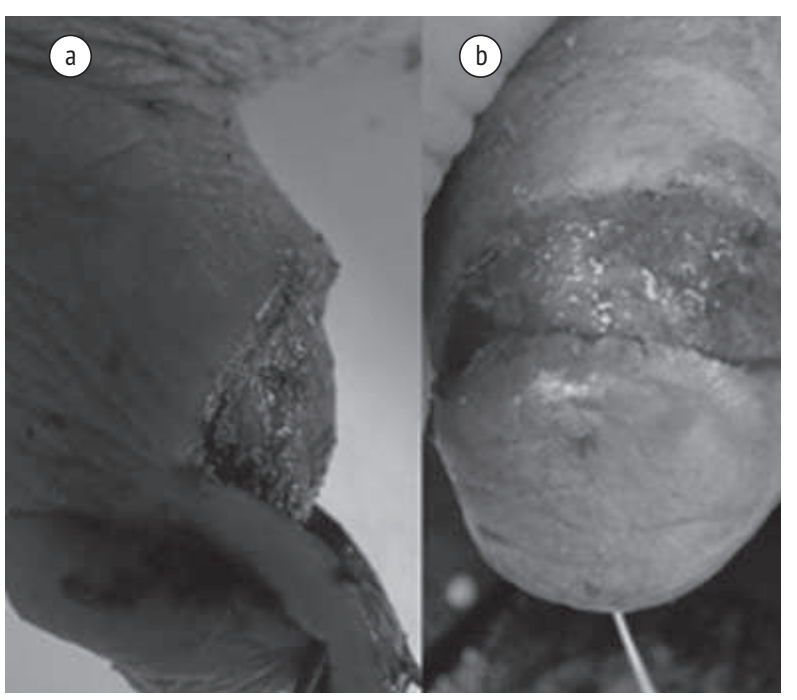

Figura 1 a e b - Ferida não perfurante em teto bovino, afetando a pele e a camada muscular (flap) antes e após a limpeza da ferida

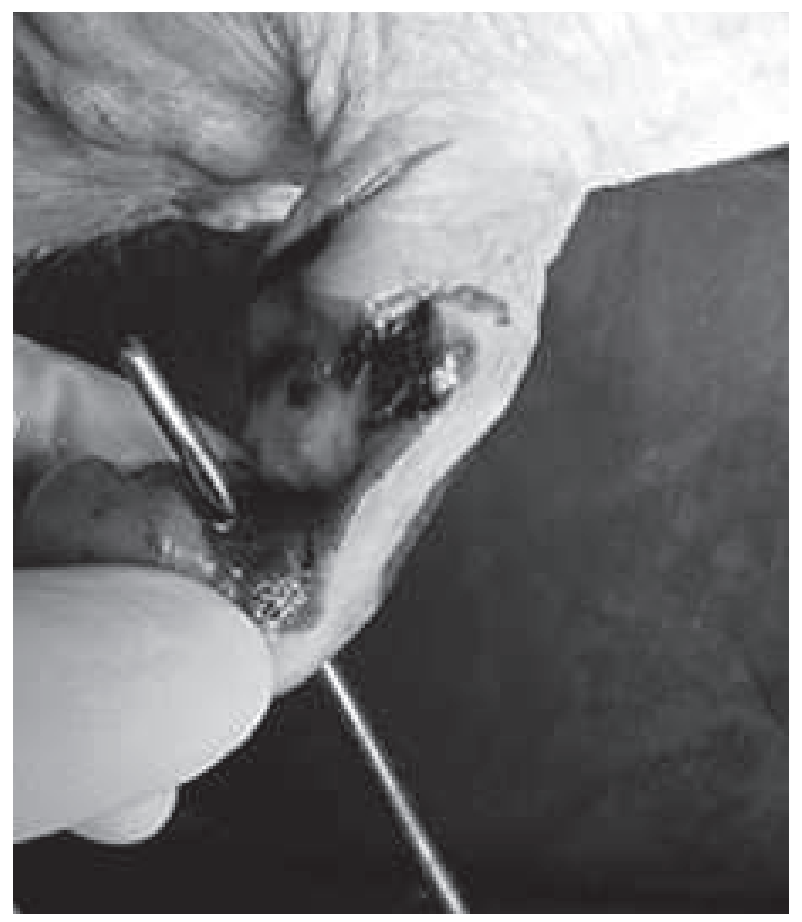

Figura 2 - Lesão lacerante e perfurante da cisterna do teto bovino. A sonda mamária metálica foi inserida pelo canal do teto. A pele, a camada muscular e a mucosa do teto foram traumatizados 


\section{Estratégias de tratamento de lesões de teto}

\section{Cuidados cirúrgicos de lesões expostas de teto}

\section{Pré-operatório}

Para uma intervenção cirúrgica, o animal deverá ser sedado (xilazina $0,05 \mathrm{mg} / \mathrm{kg}$ peso corporal, IV) e contido. 0 procedimento pode ser feito em posição quadrupedal, porém a vaca em decúbito lateral facilita a execução. Para todas as intervenções que extrapolam um simples exame da ferida, recomenda-se escoar o leite da mama afetada antes do processo cirúrgico (cânula de esgotamento do leite precedido de 20 UI de ocitocina IV). Além disso, deverá ser fixado um garrote do tipo Esmarch ou duas pinças intestinais do tipo Doyen na base do teto para reter o sangue do local. Somente após é possível proceder a anestesia local (injetar ao redor da ferida ou infiltração circular da base do teto ou anestesia IV em qualquer veia do teto e ventralmente ao garrote; 8-10 $\mathrm{ml} \mathrm{de}$ cloridrato de procaína a $2 \%$ ).

Intervenções cirúrgicas sem anestesia local, mesmo que rápidas, como preconizado por Gordo et al. (2004), não se justificam em função do bem-estar animal. Antes da intervenção cirúrgica, deverá ser aplicado um tratamento antiflogístico e analgésico (2,2 mg de flunixina meglumine, IV) e antibioticoterapia (hidroiodeto de penetamato, 10 milhões de UI, IM). Esse tratamento deverá se seguir por dois dias consecutivos no pós-operatório.

\section{Revisão da ferida e tratamento conservador}

Um tratamento dessa natureza visa obter uma cicatrização por segunda intenção. A aplicação restringe-se às lesões superficiais, feridas descascadas não perfurantes e ferimentos da ponta dos tetos com a manutenção do canal do teto. A conduta conservadora também é indicada em inflamações necróticas ou flegmonosas das feridas ou em complicações pós-cirúrgicas, que impedem totalmente ou naquele momento uma intervenção cirúrgica (GRUNERT; AHLERS, 1996). Isso é válido igualmente para ferimentos ocorridos há mais de oito horas e nos casos em que uma cicatrização por primeira intenção não possa mais ser esperada.
O objetivo da toalete da ferida é a retirada do tecido necrosado, resguardando-se o tecido saudável. As bordas da ferida são alisadas e as eventuais bolsas de mucosa ou de pele são removidas (Figura 3 a). Isso deverá evitar a hipergranulação, além de facilitar a epitelização (Figura 3 b).

\section{Cirurgia com manutenção do teto}

Ferimentos recentes (até oito horas) poderão ser suturados, desde que tenha havido a manutenção do canal do teto e uma adaptação das bordas, sem o risco de uma constrição da cisterna do teto.

Ao contrário, ferimentos transversais e perfurantes rotineiramente sinalizam um prognóstico ruim. Inicia-se com a toalete da ferida, resguardando-se o tecido vivo. As bordas da lesão são preparadas de tal maneira, que a pele do teto poderá ser levantada, formando uma crista lesional (divulsionar 2-3 mm) para a sutura (pontos em "U" separados, fio de nylon não absorvível, pseudomonofílico, 3/0) ou para a colocação dos grampos (grampos de Michel, $16 \mathrm{~mm}$ ). Em feridas perfurantes, realiza-se a adaptação em diferentes camadas, sendo a mucosa fechada por meio de sutura não perfurante (sutura de Lembert modificada, em estilo colchoeiro, com fio absorvível de gliconato 3/0, Monosyn ${ }^{\circledR}$, B. Braun).

\section{Amputação do teto fechada}

Em arrancamentos parciais (Figura 2) ou totais, perda do canal do teto, ferimentos extensos descascados ou de flap, rasgos horizontais ou transversais extensos, ferimentos por esmagamento profundo dos tetos, ou em casos prolongados, ao não se aventar a possibilidade do restabelecimento da funcionalidade do teto, este deverá ser amputado.

É contraindicada a amputação fechada nos casos de mastites, telites agudas e edemas severos de úbere (FRERKING et al., 1968; GRUNERT; AHLERS, 1996). Se ainda houver tecido de teto suficiente, o teto deverá ser retirado $2 \mathrm{~cm}$ abaixo da inserção no úbere, dentro do tecido saudável, evitando-se deixar o teto longo demais em virtude do risco de recidivas. Para conseguir-se uma adaptação ideal das bordas das feridas, disseca-se a pele do teto 


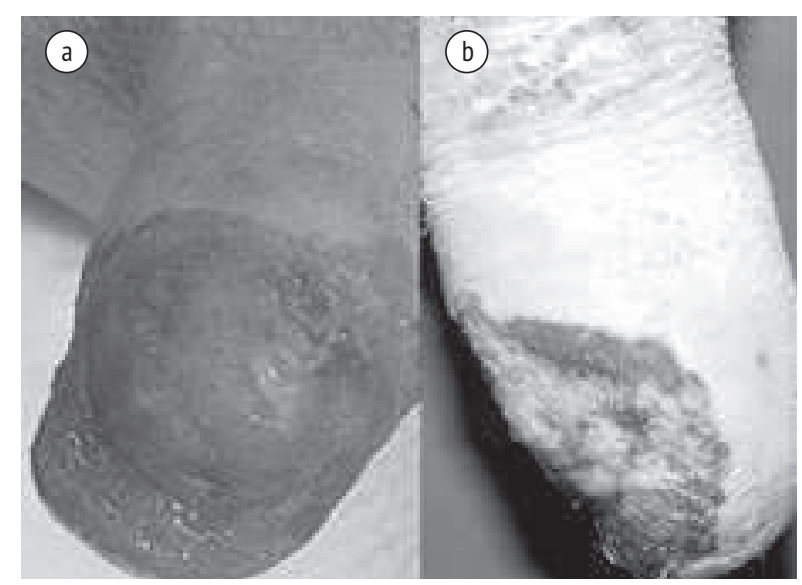

Figura 3a e b - Teto bovino após a toalete da ferida realizada (a) e epitelização desejada (b)

aproximadamente 1-2 $\mathrm{cm}$ da mucosa do teto e da camada vascular-muscular.

A oclusão ocorre em três níveis. Inicialmente, sutura-se a mucosa com sutura de Lembert modificada, em estilo colchoeiro, com fio absorvível de gliconato 3/0, Monosyn ${ }^{\circledR}$, B. Braun. Antes do fechamento definitivo do quarto mamário, este recebe um tratamento metafilático com antibiótico $(75 \mathrm{mg}$ de sulfato de cefquinoma, intracisternal). Em seguida, a camada vasculo-muscular é adaptada com sutura de Lembert contínua, com fio absorbível de gliconato 3/0 Monosyn $^{\circledR}$, B. Braun. A pele é, então, fechada com uma camada de grampos Michel de $16 \mathrm{~mm}$.

\section{Amputação do teto aberta}

Indica-se uma amputação do teto aberta quando, pelos motivos relacionados na amputação fechada, o teto não mais puder ser mantido e houver constatação de mastite naquela mama, pois ela exclui a possibilidade de uma amputação fechada. Indica-se, igualmente, a ressecção total de tetos de uma mama com mastite grave, da qual a secreção não pode mais ser escoada ou ordenhada.

Para a amputação aberta do teto, este é seccionado aproximadamente a $2 \mathrm{~cm}$ abaixo da inserção no úbere, incisando-se dentro do tecido saudável. Por meio de pontos simples ou da sutura de Kürschner com fio não absorvível, pseudomonofílico de nylon, 3/0 Filovet-Bengen ${ }^{\circledR}$, a mucosa da cisterna do teto é fixada à pele externa. Em virtude do processo inflamatório ou do edema pós-cirúrgico, a abertura do quarto poderá sofrer um estreitamento, o qual impede o escoamento livre da secreção. Por isso, recomenda-se a inserção de uma cânula de borracha ou plástico na cisterna do teto no coto de amputação, fixada por meio de pontos simples separados (Figura 4).

\section{Conduta pós-cirúrgica (operatória)}

Após a intervenção cirúrgica, o teto deve ser protegido com a colocação de uma bandagem. 0 quarto afetado é tratado localmente com um antibiótico de amplo espectro (75 mg de sulfato de cefquinoma, intracisternal) e a conduta subsequente dependerá da presença ou não de uma mastite. Como a ordenha perturba o processo cicatricial, o quarto em questão deverá ser seco, na dependência do tipo e da extensão da lesão, por um período variável de, no mínimo, duas semanas e, em casos de lesões extensas, até a cicatrização por 6-8. Essa medida não somente diminui o custo terapêutico, mas também o risco de uma infecção ascendente durante a retirada do leite.

Conduta sem a presença da mastite: 0 quarto afetado poderá ser seco momentaneamente sob proteção antibiótica (75 mg de sulfato de cefquinoma, intracisternal) e deve ser controlado por palpação diária. Em vacas saudáveis, a consistência do úbere estará inicialmente repleta e tensa, porém não flegmonosa. Após aproximadamente seis dias, a pressão intramamária diminuirá em razão da reabsorção do leite e da redução da produção láctea. Em casos não complicados, após 14 dias, o úbere terá consistência macia. Na dependência da produção láctea, imediatamente antes da operação a secreção deverá ser avaliada em intervalos regulares (primeiro controle da secreção: produção de leite $<25 \mathrm{~kg} /$ dia após 14 dias, $>25 \mathrm{~kg} /$ dia após 4 dias pós-operação; segundo controle da secreção: produção láctea $<25 \mathrm{~kg} /$ dia somente em caso de suspeita, > $25 \mathrm{~kg} /$ dia após 14 dias p.op.; terceiro controle da secreção: produção láctea $>25 \mathrm{~kg} /$ dia após 28 dias p.op.). Caso nos controles palpatórios diários e na secreção nenhum indício seja verificado sinalizando uma complicação, o quarto poderá permanecer seco até a cicatrização do defeito.

Conduta com a presença da mastite: Nesse caso, o quarto deverá ser retirado (escoado) leite 


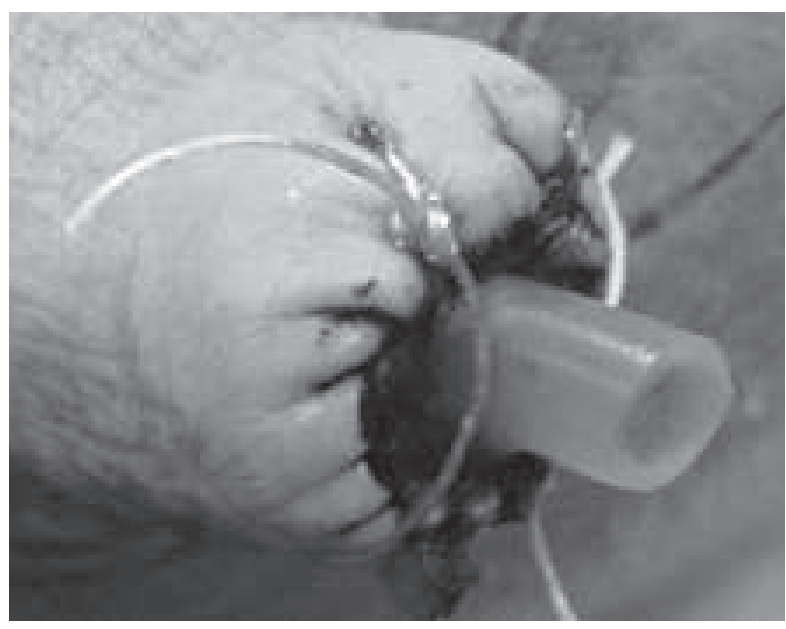

Figura 4 - Cânula de borracha fixada por meio de sutura de Kürschner no coto de amputação do teto bovino, com o fio não absorvível.

diariamente, sob condições de esterilidade. Ao final de cada retirada do leite, o quarto deverá ser protegido por antibiótico (inicialmente de amplo espectro - $75 \mathrm{mg}$ de sulfato de cefquinoma, intracisternal), e tal procedimento deverá se repetir até a cicatrização da mastite. Os pontos simples ou os grampos deverão ser retirados entre 7-10 dias após a operação. 0 tecido cicatricial da lesão, no entanto, ainda não é plenamente resiliente. Um início de ordenha deverá ocorrer, quando muito cedo, após outros 4-5 dias, com muito cuidado.

\section{Cuidados cirúrgicos de lesões do teto fe- chadas (estruturas internas)}

Em lesões do teto fechadas, depara-se, na maioria dos casos, com descolamentos parciais ou totais da mucosa associados às dificuldades na ordenha. Quanto mais alta (superior) for a lesão dentro do teto, pior será o prognóstico. Frequentemente o médico-veterinário é consultado em casos prolongados, complicados por uma telite ou mastite.

O objetivo será reconstituir a possibilidade de ordenha do teto. Para tanto, deverão ser retirados flaps de mucosa e tecido cicatricial, ou o canal do teto deverá ser dilatado, o que é cirurgicamente possível sob controle palpatório com diferentes instrumentos via canal do teto (GRUNERT; AHLERS, 1996). Alternativamente, a intervenção cirúrgica também poderá ser realizada por meio de uma endoscopia lateral (FOITZIK, 2001; GHELLER et al., 2007).

Se uma telite aguda causar a dificuldade ou a impossibilidade de ordenha, ou esta tiver complicado uma lesão prévia, primeiramente deverá ser aguardada a cura da telite antes da intervenção cirúrgica. 0 quarto afetado para tanto deverá ser seco, temporariamente, por 14 dias.

Exceção é a mastite, quando a secreção não pode ser retirada nem sob ordenha, nem sendo escoada via cânula. Nesses casos, é necessária uma imediata abertura do canal do teto (via corte em cruz do canal, faca dupla dinamarquesa). Após o término do tratamento cirúrgico, o quarto deverá ser protegido com antibiótico (75 mg de sulfato de cefquinoma, intracisternal). Caso o defeito esteja localizado no canal do teto, há a necessidade da introdução de pinos de teto para a manutenção da abertura do canal (Cera: Thelasel ${ }^{\circledR}$, Selectavet, ou silicone: SIMPL $^{\circledR}$, profs-products.com), além da colocação de uma bandagem (STARKE et al., 2007). Os pinos deverão ser introduzidos sob cuidados de assepsia e deverão ser renovados após cada troca de curativo ou retirada do leite.

\section{Conduta sem a presença da mastite}

Existem vários esquemas para os cuidados pós-cirúrgicos. Uma das maneiras é controlar, por meio da palpação, o quarto afetado diariamente e deixar de ordenhá-lo por três dias. Já no terceiro e no sexto dias, realiza-se uma avaliação da secreção, o leite é escoado por completo e o quarto é protegido com antibiótico (75 mg de sulfato de cefquinoma, intracisternal).

\section{Conduta com a presença da mastite}

Nos casos em que ocorre uma mastite concomitantemente, recomenda-se ordenhar o quarto ao menos uma vez ao dia, ou escoar o leite e tratá-lo em seguida (inicialmente com antibiótico de amplo espectro $75 \mathrm{mg}$ de sulfato de cefquinoma, intracisternal, tratamento subsequente de acordo com o antibiograma). Caso a lesão não esteja complicada por uma telite/ mastite, a duração do tratamento pós-cirúrgico de uma lesão de teto fechada é de, aproximadamente, seis ou, em casos graves, dez dias. 0 quarto temporariamente 
pouco ordenhado poderá ser ordenhado regularmente em seguida, mantendo-se um controle palpatório do teto. Nos casos da presença de uma telite ou mastite, a evolução dependerá da cura destas.

\section{Conclusões}

Para qualquer tipo de lesão traumática de teto, um preceito básico é que uma intervenção precoce causa melhoria do prognóstico. Com poucas exceções, a retirada do leite ocorre de forma incompleta (dor - inibição da ação da ocitocina, movimentos de defesa, estenose).

Por conta disso e do aumento da pressão infecciosa decorrente da lesão, frequentemente ocorrem mastites; porém, mesmo sem estas, o fluxo de leite nos quartos afetados é nitidamente retardado. Frequentemente, esses animais continuam sendo ordenhados mecanicamente, desconsiderando-se os fatos descritos aqui. Além disso, a irritação constante e prolongada da ordenha mecânica, normalmente, leva a uma telite. Vale ressaltar, então, que essas complicações (telite, mastite) dificultam a terapia ou, até mesmo, impossibilitam-na.

Uma secagem temporária e controlada do quarto afetado sempre é benéfica para a evolução da cura. Se o quarto voltar a ser ordenhado dentro de um período de 14 dias, ocorrerá somente uma perda produtiva moderada (10\%). Caso a cura leve mais tempo ou o animal se encontre no final da lactação, a possibilidade de uma secagem definitiva deverá ser aventada (GRUNERT; AHLERS, 1996).

\section{Referências}

EDLER, B. Untersuchungen zur Zitzenamputation bei Milchkühen: Ursachen, Heilungsverlauf und Wirtschaftlichkeit. 1993. 189 f. Tese (Doutorado em Medicina Veterinária) - Escola Superior de Medicina Veterinária de Hannover, 1993.

FOITZIK, D. Vergleich der postoperativen Behandlung von Zitzenkanalstenosen bei Milchkühen mittels Wollzitzenstift oder Keratelin Zäpfchen nach Geishauser® unter endoskopischer Kontrolle. 2001. 122 f. Tese (Doutorado em Medicina Veterinária) - Escola Superior de Medicina Veterinária de Hannover, 2001.
FRERKING, H. et al. Zitzenamputation beim Rind mit neuem Wundverschluss. Deutsche Tierärztliche Wochenschrift, Hannover, v. 75, p. 234-246, 1968.

GHELLER, V. A. et al. Uso de dilatador temporário em papilas mamárias de vacas, submetidas a lesões experimentais. Arquivo Brasileiro de Medicina Veterinária e Zootecnia, v. 59, n. 6, p. 1359-1367, 2007.

GORDO, J. M. L. et al. Correção da estenose do ducto papilar de vacas leiteiras com instrumento cirúrgico em forma de lanceta. Ciência Animal Brasileira, v. 5, n. 1, p. 55-61, 2004.

GRUNERT, E.; AHLERS, D. Chirurgische Versorgung von Euter- und Zitzenwunden sowie Behandlung von Zitzenstenosen. In: GRUNERT, E. Buiatrik, Band I. 5. Aufl. Hannover: Verlag Schaper, 1996. p. 172-175.

GÖTZE, R. Über Weidekrankheiten des Rindes. Deutsche Tierärztliche Wochenschrift, Hannover, v. 50, p. 281286, 1942.

STARKE, A. et al. Die Behandlung gedeckter und offener Zitzenverletzungen. Klauentierpraxis, v. 15, n. 2, p. 4043, 2007.

Recebido: $18 / 07 / 2011$

Received: 07/18/2011

Aprovado: $24 / 10 / 2011$

Approved: 10/24/2011 